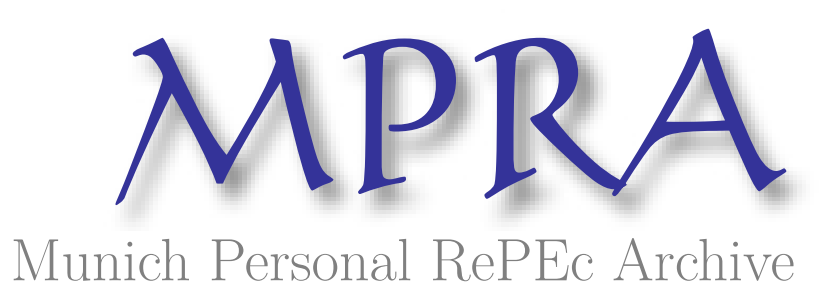

\title{
Asset Liability Management in Insurance Company
}

Giandomenico, Rossano

June 2006

Online at https://mpra.ub.uni-muenchen.de/18843/

MPRA Paper No. 18843, posted 04 Dec 2009 23:21 UTC 


\title{
Asset Liability Management in Insurance Company
}

\author{
Rossano Giandomenico
}

\begin{abstract}
The model, by using the option theory, determines the fair value of the insurance life policies with different time of maturity and shows that the effective liabilities duration of an Insurance Company exposed to the default risk is different from the duration of a default free zero coupon bond with the same time of maturity. Furthermore, it shows that the value of equity can be immunized in a dynamic way with respect to the movement of the spot rate by selling and purchasing the default free bonds in the firm asset. Moreover, the equity value, by the right bond allocation, can be immunized without varying continually the weight of the bonds on the firm asset. Furthermore, it considers the surrender option and the mortally issue such that it corrects some pitfalls that are commonly encountered in the insurance industry.
\end{abstract}

\section{Introduction}

The eighties crisis was very informative for Insurance Companies, in fact, 198 companies went bankrupt. This pointed out the question on the fair valuation of insurance liabilities and on the risk embedded in them. The fair valuation of insurance liabilities was computed without taking in account the default risk. The most used credit risk approaches are structural model and reduced form model. The reduced form approach was devised by statisticians and can be found in Duffie and Singleton (1997), Jarrow and Turnbull (1995), and Lando (1998). The problem of this approach is that you don't know where the probability of default comes from. The structural model was developed by Black, Scholes(1973) and it has the attractive feature to link the default probabilities to the company balance sheet and the risk associated to the dynamic of assets. Merton(1974) has presented the structural model in more rigorous way and has studied its behaviour. The drawback of the structural model is the assumption that the default can happen just at maturity of the debt. This lead Black, Cox(1976) to consider the case of default when the value of assets touches a barrier time dependent; in this case the default can happen before of maturity. In opposite, Longstaff, Schwartz(1995) pointed out that is not important the level of the barrier but the ratio between the value of assets and the debt. Briys, De Varenne(1997) extended the analysis to case of stochastic interest rate by assuming the barrier as function of interest rate. An alternative characterization was given by considering the equity value as knock out Call option. The drawback of these models is that they consider just a single debt; this lead Geske(1977) to consider multiple debts by using a compound option approach where the company has always short debt. The structural model has the appealing feature to permit to measure the effective liabilities duration of the company. In fact, it is through the convexity and duration analysis that the risk embedded in the insurance liabilities can be assessed. The first, to apply the structural model for Insurance Companies in asset liability management context were Briys, De Varenne(1994). Although, they used a single debt model, the duration measure proposed has the appealing feature to approximate the duration of the multi debts model. The model presented here goes along this line by using a multi debts model such that can be applied for Insurance Companies. The duration measure of assets and liabilities are presented so to analyze the mismatch between them in order to avoid that a movement of interest rate jeopardizes the equity value. 


\section{The model and its assumptions}

The model considers the insurance life policies (Universal Life) with two different time of maturity and without participation to the profit, but an extension to the case is easy enough. The cash value of a Universal Life contract typically earns a minimum guaranteed rate of return. The model enables to determine the fair fixed guaranteed interest rate, and in the case of participation to the profit the fair participation level, that policyholders should require to compensate them fully for the risks they face. In other words, the model yields the fair price of the insurance liabilities given the current structure of the company balance sheet. The basic idea, as it was developed by Black, Scholes(1973), is that the equity value of a levered firm can be valued as contingent claim on the value of the company. In fact, if at the time of maturity of the debt the value of the company is less or equal to the debt itself, the equity value is nil (out-of-money) and the company is declared insolvent. Along the same line we explore the case of the debt with different time of maturity and it leads us to conclude that the equity value is a compound option, or an option on option. At start time the Insurance Company acquires an asset portfolio $\mathrm{A}_{t}$ and finances this portfolio with paid in capital $\mathrm{E}_{t}$ and the premiums of the insurance life policies $\mathrm{L}_{t}$. The portfolio of assets is assumed to be totally invested in risky assets (equity, bonds, derivatives, real estate...). Thus, the first risk element of the firm asset is interest rate risk (bonds) and the second element of risk is asset risk (equity, derivatives, real estate...) that is all risk affecting assets other than interest rate risk. As result, the value of the portfolio of assets $A_{t}$ is governed by a stochastic process whose path is affected by both asset risk and interest rate risk at the same time.

$$
d \mathrm{~A}_{t} / \mathrm{A}_{t}=\mu d t+\sigma_{\mathrm{A}}\left[\rho(\mathrm{A}, r) d W_{r}+\sqrt{1-\rho(\mathrm{A}, r)^{2}} d W_{s}\right]
$$

$\mu \quad$ denotes the drift of the process

$d W_{s}$ denotes a standard Wiener process independent of $d W_{r}$ capturing the assets-risk other than the interest rate risk

$d W_{r}$ denotes a standard Wiener process capturing the interest rate risk

$\sigma_{\mathrm{A}}$ denotes the instantaneous volatility of assets

$\rho(\mathrm{A}, r)$ represents the correlation between the total value of assets and the spot rate $r_{t}$

In other words $\rho(\mathrm{A}, r)$ corresponds to the share of interest rate risk in the total risk of the assets. More specifically, the total variance of assets $\sigma_{\mathrm{A}}{ }^{2}$ can be split into two parts: an interest rate risk component $\rho(\mathrm{A}, r)^{2} \sigma_{\mathrm{A}}{ }^{2}$ and an asset risk component $\left[1-\rho(\mathrm{A}, r)^{2}\right] \sigma_{\mathrm{A}}{ }^{2}$.

Insurance and financial markets are assumed to be competitive. Therefore, the Insurance Company is a price-taker such that it has to service policyholders on a market basis. Our time horizon is $T>\tau>t$. We denote with $\mathrm{L}_{1} *$ the final value of the debt with time of maturity $\tau$, and with $\mathrm{L}_{2} *$ the final value of the debt with time of maturity $T$, and the respective initial value of the insurance life policies with $\mathrm{B}_{1}(t, \tau)$ and with $\mathrm{B}_{2}(t, T)$. We can see analytically how the equity value can be valued as a contingent claim by using the final pay off at time $\tau$ :

$$
\mathrm{E}_{\tau}+\mathrm{B}_{2}(\tau, T)=\max \left[0, \mathrm{~A}_{\tau}-\mathrm{L}_{1} *\right]
$$

We can note that this is the same final pay off of a long position on a Call option written on the company value $\mathrm{A}_{t}$ and with exercise price $\mathrm{L}_{1} *$.

As such, their initial value is given by:

$$
\mathrm{E}_{t}+\mathrm{B}_{2}(t, T)=\mathrm{C}\left(\mathrm{A}_{t}, \mathrm{~L}_{1}^{*}, \tau-t\right)
$$


We denote with $C(\ldots)$ the value of European Call option on the firm's underlying asset $A_{t}$ maturing at time $\tau$ and with exercise price $\mathrm{L}_{1} *$.

Therefore, we have the following final pay off for the insurance life policies with time of maturity $\tau$ :

Where:

$$
\mathrm{B}_{1}(\tau, \tau)=\min \left[\mathrm{L}_{1}^{*}, \mathrm{~A}_{\tau}\right]
$$

$$
\mathrm{B}_{1}(\tau, \tau)-\mathrm{L}_{1}^{*}=\min \left[\mathrm{A}_{\tau}-\mathrm{L}_{1} *, 0\right]
$$

At this point, we can note that this is the same final pay off of a short position on a Put option written on the company value $\mathrm{A}_{t}$ and with exercise price $\mathrm{L}_{1} *$.

Thus, we have:

$$
\mathrm{B}_{1}(\tau, \tau)-\mathrm{L}_{1}^{*}=-\max \left[\mathrm{L}_{1} *-\mathrm{A}_{\tau}, 0\right]
$$

This result is intuitive; it reflects the option of stakeholders to walk away if things go wrong. Straightforward, the initial value of the insurance life policies with time of maturity $\tau$ is:

$$
\mathrm{B}_{1}(t, \tau)=\mathrm{L}_{1} * \mathrm{P}_{1}(t, \tau)-\mathrm{P}\left(\mathrm{A}_{t}, \mathrm{~L}_{1}^{*}, \tau-t\right)
$$

We denote with $\mathrm{P}(\ldots)$ the value of European Put option on the firm's underlying asset $\mathrm{A}_{t}$, maturing at time $\tau$ and with exercise price $\mathrm{L}_{1}{ }^{*}$, and with $\mathrm{P}_{1}(t, \tau)$ the price of a default free zero coupon bond maturing at time $\tau$ such that $\mathrm{P}_{1}(\tau, \tau)=1$. Now it is easy to note that the equity value is an European Call option written on the Call option $\mathrm{C}\left(\mathrm{A}_{t}, \mathrm{~L}_{1}{ }^{*}, \tau-t\right)$, but the fact that our underlying is an option can seem a problem to get its dynamic in the time.

Anyway, if we consider that $\mathrm{C}\left(\mathrm{A}_{t}, \mathrm{~L}_{1}{ }^{*}, \tau-t\right)$ matures at time $\tau$ and converges to its final pay off: $\max \left[0, \mathrm{~A}_{\tau}-\mathrm{L}_{1} *\right]$, where $\mathrm{L}_{1}^{*}=\mathrm{B}_{1}(t, \tau) e^{\left[r^{*}(\tau-t)\right]}$ and $r^{*}$ denotes the fixed guaranteed interest rate, we can conclude that our effective underlying is:

$$
\mathrm{C}\left(\mathrm{A}_{t}, \mathrm{~L}_{1}^{*}, \tau-t\right)=\mathrm{A}_{t}-\mathrm{B}_{1}(t, \tau)
$$

Thus, we can assume that the dynamic of the value of $\mathrm{A}_{t}-\mathrm{B}_{1}(t, \tau)$ is given by the following stochastic continuous process:

$$
d\left[\mathrm{~A}_{t}-\mathrm{B}_{1}(t, \tau)\right] /\left[\mathrm{A}_{t}-\mathrm{B}_{1}(t, \tau)\right]=\mu_{t} d t+\sigma_{\mathrm{A}}\left[\rho(\mathrm{A}, r) d W_{r}+\sqrt{1-\rho(\mathrm{A}, r)^{2}} d W_{s}\right]
$$

Where the drift is stochastic because the process reverts to the value of the final pay off, this is not a problem to get the value of the compound option because the hedging relation permits us to consider the spot rate like drift. $\left(1^{*}\right)$ Along the same line we get the initial value of equity and the initial value of the insurance life policies with time of maturity $T$ :

$$
\begin{gathered}
\mathrm{E}_{t}=\mathrm{C}\left(\mathrm{A}_{t}-\mathrm{B}_{1}, \mathrm{~L}_{2} * T-t\right) \\
\mathrm{B}_{2}(t, T)=\mathrm{L}_{2} * \mathrm{P}_{2}(t, T)-\mathrm{P}\left(\mathrm{A}_{t}-\mathrm{B}_{1}, \mathrm{~L}_{2} *, T-t\right)
\end{gathered}
$$


We denote respectively, with $\mathrm{C}(\ldots)$ and $\mathrm{P}(\ldots)$, the value of European Call option and the value of European Put option on the firm's underlying asset $\mathrm{A}_{t}-\mathrm{B}_{1}$, maturing at time $T$ and with exercise price $\mathrm{L}_{2}{ }^{*}$. $\left(2^{*}\right)\left(3^{*}\right)$ We can note that the model is consistent with the Modigliani-Miller theorem. In fact, we have:

$$
\mathrm{A}_{t}=\mathrm{E}_{t}+\mathrm{B}_{1}(t, \tau)+\mathrm{B}_{2}(t, T)
$$

At this point, we can note that the dynamic and the volatility of a default free zero coupon bond is different for each model we can use. The Vasicek(1977) model assumes that the dynamic of the spot rate is given by the following mean-reverting process:

$$
d r_{t}=\left(b-a r_{t}\right) d t+\delta_{r} d W_{r}
$$

Where $a$ and $b$ are valued on the base of market preferences and $\delta_{r}$ denotes the instantaneous volatility of the spot rate. While, the prices of the riskless securities $\mathrm{P}_{1}(t, \tau)$ and $\mathrm{P}_{2}(t, T)$ are given by:

$$
\mathrm{P}_{1}(t, \tau)=\exp \left[\mathrm{G}(t, \tau)-H(t, \tau) r_{t}\right]
$$

Where:

$$
\begin{gathered}
H(t, \tau)=(1 / a)\left[1-e^{-a(\tau-t)}\right] \\
\mathrm{G}(t, \tau)=\frac{[H(t, \tau)-\tau+t]\left(a b-1 / 2 \delta_{r}^{2}\right)}{a^{2}}-\frac{\delta_{r}^{2} H^{2}(t, \tau)}{4 a} \\
\mathrm{P}_{2}(t, T)=\exp \left[\mathrm{G}(t, T)-H(t, T) r_{t}\right]
\end{gathered}
$$

Where:

$$
\begin{gathered}
H(t, T)=(1 / a)\left[1-e^{-a(T-t)}\right] \\
\mathrm{G}(t, T)=\frac{[H(t, T)-T+t]\left(a b-1 / 2 \delta_{r}^{2}\right)}{a^{2}}-\frac{\delta_{r}^{2} H^{2}(t, T)}{4 a}
\end{gathered}
$$

Now, if we put the following interest rate elasticity measure:

$$
\begin{aligned}
\eta_{\mathrm{p}(t, \tau)} & =-\left[1 / \mathrm{P}_{1}(t, \tau)\right]\left[\partial \mathrm{P}_{1}(t, \tau) / \partial r_{t}\right] \\
\eta_{\mathrm{p}(t, T)} & =-\left[1 / \mathrm{P}_{2}(t, T)\right]\left[\partial \mathrm{P}_{2}(t, T) / \partial r_{t}\right]
\end{aligned}
$$

We have the following:

$$
\begin{gathered}
\eta_{\mathrm{p}(t, \tau)}=H(t, \tau) \\
\eta_{\mathrm{p}(t, T)}=H(t, T)
\end{gathered}
$$


Thus, the instantaneous volatilities of the riskless securities $\mathrm{P}_{1}(t, \tau)$ and $\mathrm{P}_{2}(t, T)$ are respectively:

$$
\begin{gathered}
\sigma_{\mathrm{p}}(t, \tau)=\delta_{r} H(t, \tau) \\
\sigma_{\mathrm{p}}(t, T)=\delta_{r} H(t, T)
\end{gathered}
$$

While, the dynamics of the riskless securities $\mathrm{P}_{1}(t, \tau)$ and $\mathrm{P}_{2}(t, T)$ are given by the following stochastic continuous processes:

$$
\begin{aligned}
d \mathrm{P}_{1}(t, \tau) / \mathrm{P}_{1}(t, \tau) & =r_{t} d t-\sigma_{\mathrm{p}}(t, \tau) d W_{r} \\
d \mathrm{P}_{2}(t, T) / \mathrm{P}_{2}(t, T) & =r_{t} d t-\sigma_{\mathrm{p}}(t, T) d W_{r}
\end{aligned}
$$

Now we assume that we have the following portfolio of default free zero coupon bonds in the assets:

$$
\mathrm{V}_{t}=\lambda \mathrm{P}_{1}(t, \tau)+(1-\lambda) \mathrm{P}_{2}(t, T)
$$

Where:

$$
\begin{gathered}
\lambda=\mathrm{p}\left(\mathrm{A}, \mathrm{P}_{1}\right) / \mathrm{p}(\mathrm{A}, \mathrm{V}) \\
1-\lambda=\mathrm{p}\left(\mathrm{A}, \mathrm{P}_{2}\right) / \mathrm{p}(\mathrm{A}, \mathrm{V}) \\
\mathrm{p}(\mathrm{A}, \mathrm{V})=\mathrm{p}\left(\mathrm{A}, \mathrm{P}_{1}\right)+\mathrm{p}\left(\mathrm{A}, \mathrm{P}_{2}\right) \leq 1
\end{gathered}
$$

$\mathrm{p}(\mathrm{A}, \mathrm{V})$ denotes the weight of the riskless bonds portfolio $V_{t}$ on the total value of assets $\mathrm{A}_{t}$ $\mathrm{p}\left(\mathrm{A}, \mathrm{P}_{1}\right)$ denotes the weight of the riskless security $\mathrm{P}_{1}(t, \tau)$ on the total value of assets $\mathrm{A}_{t}$ $\mathrm{p}\left(\mathrm{A}, \mathrm{P}_{2}\right)$ denotes the weight of the riskless security $\mathrm{P}_{2}(t, T)$ on the total value of assets $\mathrm{A}_{t}$

The dynamic of the default free zero coupon bonds portfolio $\mathrm{V}_{t}$ is given by the following stochastic continuous process:

$$
d \mathrm{~V}_{t} / \mathrm{V}_{t}=r_{t} d t-\sigma_{\mathrm{V}} d W_{r}
$$

Where:

$$
\sigma_{\mathrm{V}}^{2}=\lambda^{2} \sigma_{\mathrm{p}}^{2}(t, \tau)+(1-\lambda)^{2} \sigma_{\mathrm{p}}^{2}(t, T)+2 \rho\left(\mathrm{P}_{1} \mathrm{P}_{2}\right) \lambda \sigma_{\mathrm{p}}(t, \tau)(1-\lambda) \sigma_{\mathrm{p}}(t, T)
$$

$\rho\left(P_{1} P_{2}\right)=1$ that is equal to assume a shift of the entire yield curve with respect to a movement of the spot rate.

It represents the correlation between the riskless security $\mathrm{P}_{1}(t, \tau)$ and the riskless security $\mathrm{P}_{2}(t, T)$

Thus, we have:

$$
\begin{gathered}
\eta_{\mathrm{V}}=\lambda \eta_{\mathrm{p}(t, \tau)}+(1-\lambda) \eta_{\mathrm{p}(t, T)} \\
\sigma_{\mathrm{V}}=\eta_{\mathrm{V}} \delta_{r}
\end{gathered}
$$


Now we compute the value of the options by using the respective numeraire $\mathrm{P}_{1}(t, \tau)$ and $\mathrm{P}_{2}(t, T)$ :

$$
\begin{aligned}
\mathrm{C}\left(\mathrm{A}_{t}, \mathrm{~L}_{1}^{*}, \tau-t\right) & =\mathrm{A}_{t} \mathrm{~N}\left[\mathrm{~d}_{1}\right]-\mathrm{P}_{1}(t, \tau) \mathrm{L}_{1} * \mathrm{~N}\left[\mathrm{~d}_{2}\right] \\
\mathrm{P}\left(\mathrm{A}_{t}, \mathrm{~L}_{1} * \tau-t\right) & =\mathrm{P}_{1}(t, \tau) \mathrm{L}_{1} * \mathrm{~N}\left[-\mathrm{d}_{2}\right]-\mathrm{A}_{t} \mathrm{~N}\left[-\mathrm{d}_{1}\right] \\
\mathrm{C}\left(\mathrm{A}_{t}-\mathrm{B}_{1}, \mathrm{~L}_{2}^{*}, T-t\right) & =\left(\mathrm{A}_{t}-\mathrm{B}_{1}\right) \mathrm{N}\left[\mathrm{h}_{1}\right]-\mathrm{P}_{2}(t, T) \mathrm{L}_{2} * \mathrm{~N}\left[\mathrm{~h}_{2}\right] \\
\mathrm{P}\left(\mathrm{A}_{t}-\mathrm{B}_{1}, \mathrm{~L}_{2} * T-t\right) & =\mathrm{P}_{2}(t, T) \mathrm{L}_{2} * \mathrm{~N}\left[-\mathrm{h}_{2}\right]-\left(\mathrm{A}_{t}-\mathrm{B}_{1}\right) \mathrm{N}\left[-\mathrm{h}_{1}\right]
\end{aligned}
$$

Where:

$\mathrm{N}[\ldots]$ denotes the cumulative normal distribution

$$
\begin{gathered}
\mathrm{d}_{1}=\quad \frac{\ln \left\{\mathrm{A}_{t} /\left[\mathrm{L}_{1} * \mathrm{P}_{1}(t, \tau)\right]\right\}+1 / 2 \sigma_{(t, \tau)}^{2}(\tau-t)}{\sigma_{(t, \tau)} \sqrt{ }(\tau-t)} \\
\mathrm{d}_{2}=\quad \frac{\ln \left\{\mathrm{A}_{t} /\left[\mathrm{L}_{1} * \mathrm{P}_{1}(t, \tau)\right]\right\}-1 / 2 \sigma_{(t, \tau)}^{2}(\tau-t)}{\sigma_{(t, \tau)} \sqrt{ }(\tau-t)} \\
\mathrm{h}_{1}=\frac{\ln \left\{\left(\mathrm{A}_{t}-\mathrm{B}_{1}\right) /\left[\mathrm{L}_{2} * \mathrm{P}_{2}(t, T)\right]\right\}+1 / 2 \sigma_{(t, T)}^{2}(T-t)}{\sigma_{(t, T)} \sqrt{ }(T-t)} \\
\mathrm{h}_{2}=\frac{\ln \left\{\left(\mathrm{A}_{t}-\mathrm{B}_{1}\right) /\left[\mathrm{L}_{2} * \mathrm{P}_{2}(t, T)\right]\right\}-1 / 2 \sigma_{(t, T)}^{2}}{\sigma_{(t, T)} \sqrt{ }(T-t)}(T-t)
\end{gathered}
$$

While:

$$
\begin{aligned}
& \sigma_{(t, \tau)}^{2}=[1 /(\tau-t)] \int_{t}^{\tau} \sigma_{\mathrm{A}}(t)^{2}+\sigma_{\mathrm{p}}(t, \tau)^{2}+2 \rho(\mathrm{A}, r) \sigma_{\mathrm{A}}(t) \sigma_{\mathrm{p}}(t, \tau) d t \\
& \sigma_{(t, T)}^{2}=[1 /(T-t)] \int_{t}^{T} \sigma_{\mathrm{A}}(t)^{2}+\sigma_{\mathrm{p}}(t, T)^{2}+2 \rho(\mathrm{A}, r) \sigma_{\mathrm{A}}(t) \sigma_{\mathrm{p}}(t, T) d t
\end{aligned}
$$

We can note that the drift of the process of assets doesn't appear in the value of the options, this is due to the fact that the hedging relation permits us to consider the spot rate like drift. Thus, the expected value of assets, that can be get by using a Monte Carlo simulation, doesn't change the fair value of equity and liabilities. Note that the total value of the insurance liabilities is:

$$
\mathrm{L}_{t}=\mathrm{L}_{1} * \mathrm{P}_{1}(t, \tau)+\mathrm{L}_{2} * \mathrm{P}_{2}(t, T)-\mathrm{P}\left(\mathrm{A}_{t}, \mathrm{~L}_{1}^{*}, \tau-t\right)-\mathrm{P}\left(\mathrm{A}_{t}-\mathrm{B}_{1}, \mathrm{~L}_{2} *, T-t\right)
$$

Where:

$$
\begin{gathered}
\mathrm{V}_{t}=\lambda \mathrm{P}_{1}(t, \tau)+(1-\lambda) \mathrm{P}_{2}(t, T) \\
\lambda=\left[\mathrm{L}_{1} * \mathrm{P}_{1}(t, \tau)\right] /\left[\mathrm{L}_{1} * \mathrm{P}_{1}(t, \tau)+\mathrm{L}_{2} * \mathrm{P}_{2}(t, T)\right] \\
(1-\lambda)=\left[\mathrm{L}_{2} * \mathrm{P}_{2}(t, T)\right] /\left[\mathrm{L}_{1} * \mathrm{P}_{1}(t, \tau)+\mathrm{L}_{2} * \mathrm{P}_{2}(t, T)\right]
\end{gathered}
$$


To achieve our aim we have to compute the elasticity measure of assets and liabilities. Thus, we put the following interest rate elasticity measure:

$$
\begin{aligned}
& \eta_{\mathrm{A}}=-\left(1 / \mathrm{A}_{t}\right)\left(\partial \mathrm{A}_{t} / \partial r_{t}\right) \\
& \eta_{\mathrm{L}}=-\left(1 / \mathrm{L}_{t}\right)\left(\partial \mathrm{L}_{t} / \partial r_{t}\right)
\end{aligned}
$$

We can compute the elasticity measure of the assets $A_{t}$ and the life insurance liabilities $\mathrm{L}_{t}$ :

$$
\begin{gathered}
\eta_{\mathrm{A}}=\mathrm{p}(\mathrm{A}, \mathrm{V}) \eta_{\mathrm{v}} \\
\eta_{\mathrm{L}}=\left[\mathrm{L}_{1} * \mathrm{P}_{1}(t, \tau) / \mathrm{L}_{t}\right] \eta_{\mathrm{p}(t, \tau)}+\left[\mathrm{L}_{2} * \mathrm{P}_{2}(t, T) / \mathrm{L}_{t}\right] \eta_{\mathrm{p}(t, T)}+\left(\mathrm{A}_{t} \eta_{\mathrm{A}} / \mathrm{L}_{t}\right)\left\{\mathrm{N}\left[-\mathrm{d}_{1}\right]+\mathrm{N}\left[\mathrm{d}_{1}\right] \mathrm{N}\left[-\mathrm{h}_{1}\right]\right\} \\
-\left[\mathrm{L}_{1} * \mathrm{P}_{1}(t, \tau) \eta_{\mathrm{p}(t, \tau)} / \mathrm{L}_{t}\right]\left\{\mathrm{N}\left[-\mathrm{d}_{2}\right]+\mathrm{N}\left[\mathrm{d}_{2}\right] \mathrm{N}\left[-\mathrm{h}_{1}\right]\right\}-\left[\mathrm{L}_{2} * \mathrm{P}_{2}(t, T) \eta_{\mathrm{p}(t, T)} / \mathrm{L}_{t}\right] \mathrm{N}\left[-\mathrm{h}_{2}\right]
\end{gathered}
$$

We can observe that if no default is possible the insurance liabilities become just a portfolio of default free bonds. The third, the fourth and the fifth term measure the impact of the derivative of Put options on the insurance liabilities duration. $(4 *)$ We can note that for a high value of the elasticity of assets the Put options increase the effective liabilities duration. Otherwise, they reduce the insurance liabilities duration. For rational values of parameters, we have the following prospect:

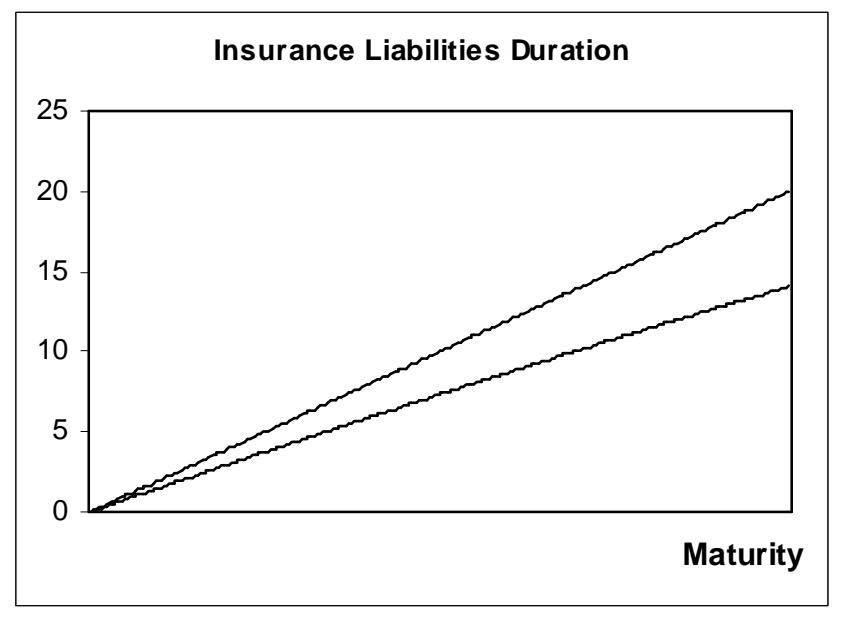

We can note that for a value of the weight of the bonds on the assets equal to the weight of the debt on the assets the Put options reduce the insurance liabilities duration. In fact, to a maturity of twenty years corresponds a duration of fourteen years. One of our assumptions is that the Modigliani-Miller theorem is valid, so the market value of equity is obviously equal to the difference between the market value of assets and the market value of liabilities. As such, its effective elasticity is directly affected by both the elasticity of assets, the elasticity of liabilities and the leverage effect. Thus, we have:

$$
\begin{aligned}
& \eta_{\mathrm{A}}=\left(\mathrm{E}_{t} / \mathrm{A}_{t}\right) \eta_{\mathrm{E}}+\left(\mathrm{L}_{t} / \mathrm{A}_{t}\right) \eta_{\mathrm{L}} \\
& \eta_{\mathrm{E}}=\left(\mathrm{A}_{t} / \mathrm{E}_{t}\right) \eta_{\mathrm{A}}-\left(\mathrm{L}_{t} / \mathrm{E}_{t}\right) \eta_{\mathrm{L}}
\end{aligned}
$$


From these equations we can see that the elasticity of equity is nil when:

$\mathrm{A}_{t} \eta_{\mathrm{A}}=\mathrm{L}_{t} \eta_{\mathrm{L}}$

Where we equal the relative variation of the market value of assets and the market value of liabilities. We can note that the liabilities and the assets exhibit a convex behaviour with respect to the interest rates, but the convexity effect is stronger on the assets side than the liabilities side. This effect is due to the presence of the Put options on the liabilities side. In fact, the derivatives of the cumulative of normal distributions decrease the convexity of liabilities. This result is certain just if the convexity of assets is greater, or equal, to the convexity of liabilities if we don't consider the impact of the derivatives of the cumulative normal distributions. For instance, if we reduce the convexity of assets the convexity of liabilities becomes stronger either if we consider the impact of the derivatives of the cumulative normal distributions. Thus, except for this cases, we can't know the spread between the convexity of assets and liabilities without a numerical model. We can note that, if we compute the value of $\mathrm{p}(\mathrm{A}, \mathrm{V})^{*}$ that makes nil the elasticity of equity for the present spot rate, the equity value is immunized with respect to small movement of the spot rate. Hence, if the convexity of liabilities is stronger than the convexity of assets the behaviour of equity value resembles to a short position on a Straddle written on the spot rate. Otherwise, the behaviour of equity value resembles to a long position on a Straddle written on the spot rate. Thus, we can immunize the equity value in a perfect way by taking a position on a Straddle written on the spot rate with opposite sign. Otherwise, given our assumption that the dynamic of the spot rate follows a stochastic continuous process, we can keep the immunization in a dynamic way by selling and purchasing the default free bonds in the firm asset. Instead, if we assume that the spot rate can have a jump, the efficacy of immunization will depend negatively by the width of the jump. Moreover, we have to note that some parameters are valued on the base of market preferences such that a change of them involves a change of $\mathrm{p}(\mathrm{A}, \mathrm{V})^{*}$, but for small change the immunization is approximately exact. Note that we got a dynamic measure of the insurance liabilities duration with respect to the spot rate and the market preferences. We can observe that if $\mathrm{b}(\mathrm{A}, \mathrm{V})>\mathrm{p}(\mathrm{A}, \mathrm{V})^{*}$ the behaviour of equity value resembles to a short position on the spot rate and that if $\mathrm{p}(\mathrm{A}, \mathrm{V})<\mathrm{b}(\mathrm{A}, \mathrm{V})^{*}$ the behaviour of equity value resembles to a long position on the spot rate. Another way to immunize the equity value is to choose the right value of $\mathrm{p}\left(\mathrm{A}, \mathrm{P}_{1}\right)$ and $\mathrm{b}\left(\mathrm{A}, \mathrm{P}_{2}\right)$ such that the elasticity of equity is nil and the convexity of assets and liabilities is equal around the present value of the spot rate. This permits us to immunize the equity value without varying continually the weight of the bonds on the firm asset. Formally, we have:

$$
\begin{gathered}
\mathrm{A}_{t} \mathrm{p}\left(\mathrm{A}, \mathrm{P}_{1}\right) \eta_{\mathrm{p}(t, \tau)}=\mathrm{L}_{1} * \mathrm{P}_{1}(t, \tau) \eta_{\mathrm{p}(t, \tau)}+\mathrm{A}_{t} \mathrm{p}\left(\mathrm{A}, \mathrm{P}_{1}\right) \eta_{\mathrm{p}(t, \tau)}\left\{\mathrm{N}\left[-\mathrm{d}_{1}\right]+\mathrm{N}\left[\mathrm{d}_{1}\right] \mathrm{N}\left[-\mathrm{h}_{1}\right]\right\} \\
-\mathrm{L}_{1} * \mathrm{P}_{1}(t, \tau) \eta_{\mathrm{p}(t, \tau)}\left\{\mathrm{N}\left[-\mathrm{d}_{2}\right]+\mathrm{N}\left[\mathrm{d}_{2}\right] \mathrm{N}\left[-\mathrm{h}_{1}\right]\right\} \\
\mathrm{A}_{t} \mathrm{p}\left(\mathrm{A}, \mathrm{P}_{2}\right) \eta_{\mathrm{p}(t, T)}=\mathrm{L}_{2} \mathrm{P}_{2}(t, T) \eta_{\mathrm{p}(t, T)}+\mathrm{A}_{t} \mathrm{p}\left(\mathrm{A}, \mathrm{P}_{2}\right) \eta_{\mathrm{p}(t, T)}\left\{\mathrm{N}\left[-\mathrm{d}_{1}\right]+\mathrm{N}\left[\mathrm{d}_{1}\right] \mathrm{N}\left[-\mathrm{h}_{1}\right]\right\} \\
-\mathrm{L}_{2} * \mathrm{P}_{2}(t, T) \eta_{\mathrm{p}(t, T)} \mathrm{N}\left[-\mathrm{h}_{2}\right]
\end{gathered}
$$

We can note that this permits us to immunize the equity value in a perfect way with respect to the market preferences and the spot rate without assuming a parallel shift of the yield curve. Furthermore, it permits us to don't assume a specific model to get the dynamic and the interest rate elasticity measure of a default free zero coupon bond. 
For rational values of parameters, we have the following prospect:

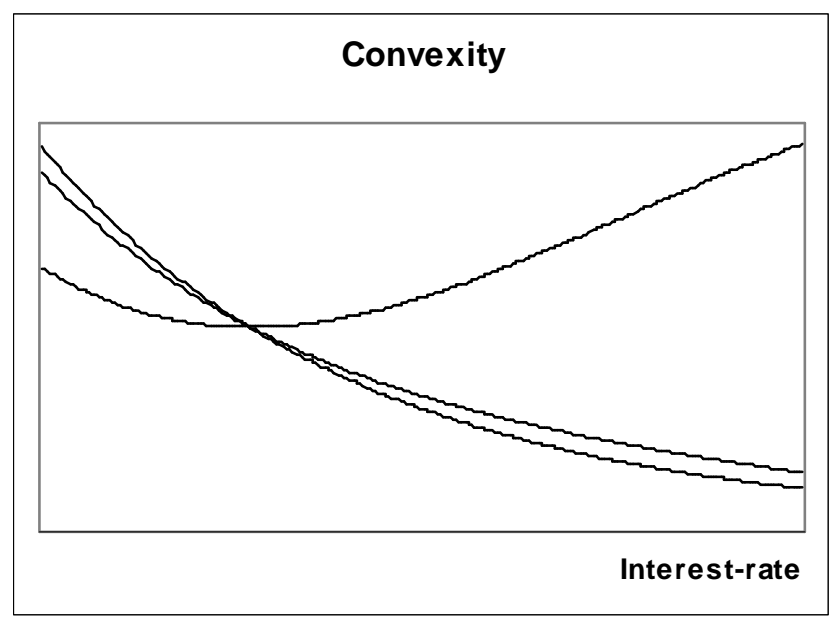

We can note that the convexity of assets and liabilities is approximately equal around the present value of the spot rate such that the equity value is approximately immunized in a perfect way. More specifically, the behaviour of equity value resembles to a long position on a Collar written on the spot rate.

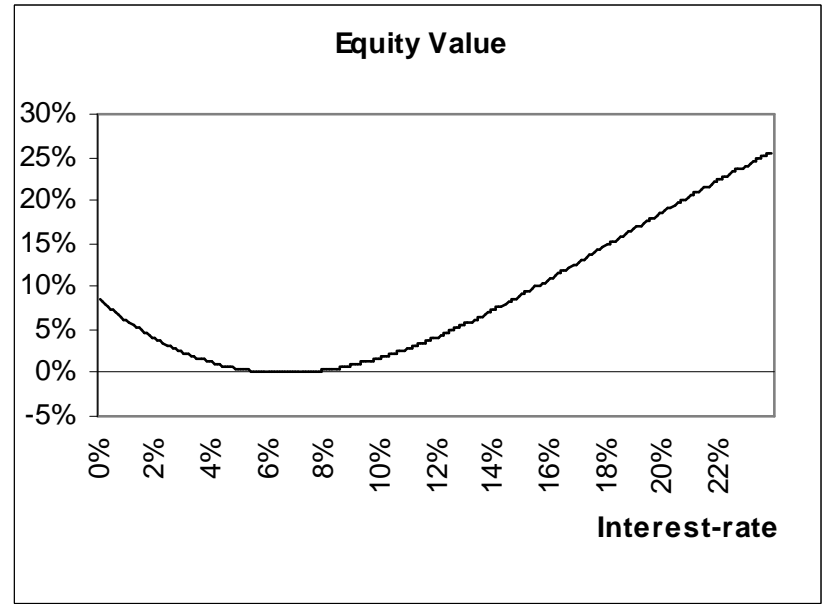

We have to note that for a big movement of the spot rate, the market preferences and the values of parameters, we have to rebalance the hedge ratio. If we consider the case of participation to the profit we have the same result. At this point, we have to note that the equity value is immunized with respect to the market value of the insurance life policies. Nevertheless, if the insurance life policies are not traded, the only way for the policyholders to get back the loan is to exercise the surrender options. Thus, if the fair value of the insurance life policies is less than the refund value, we get a loss on the equity value. However, we can consider the surrender options in the pricing of the insurance life policies by using the option theory. We can note that the surrender option is an American Put option written on the insurance life policies value. We have to note that the financial approach values the American Put option under the assumption of absence of arbitrage opportunity. As such, its value is greater than its pay off, this doesn't permit us to find a solution for the price of the insurance life policies. In fact the initial fair value of the insurance life policies is always greater than the initial premiums. However, we have to note that the surrender options may expire without being exercised. Hence, we can weigh the American Put options with the probability that they will be exercised that can depend from the market 
conditions and the mortality tables. In fact, except for the start time, there isn't an arbitrage opportunity but just an incentive to exercise the surrender options. Thus, it is rational to expect that the market value of the surrender options is less than their pay off because many of them will expire without being exercised either if they are in-the-money. Thus, we have the following:

$$
\mathrm{Q}_{1}(t, \tau)=\mathrm{L}_{1} * \mathrm{P}_{1}(t, \tau)-\mathrm{P}\left(\mathrm{A}_{t}, \mathrm{~L}_{1}^{*}, \tau-t\right)+f_{x} \mathrm{P}_{\mathrm{A}}\left(\mathrm{B}_{1}, \mathrm{~B}_{1}^{*}, \tau-t\right)
$$

Where $f_{x}$ denotes the probability that the surrender options will be exercised. $\mathrm{Q}_{1}(t, \tau)$ denotes the value of the insurance life policies with the surrender option and $\mathrm{P}_{\mathrm{A}}(\ldots)$ denotes the value of an American Put option written on the underlying $\mathrm{B}_{1}(t, \tau)$, maturing at time $\tau$ and with exercise price $\mathrm{B}_{1} *$ that represents the refund value of the insurance life policies.

Therefore, we have:

$$
\begin{gathered}
\mathrm{E}_{t}=\mathrm{C}\left(\mathrm{A}_{t}-\mathrm{Q}_{1}, \mathrm{~L}_{2} *, T-t\right)-f_{y} \mathrm{P}_{\mathrm{A}}\left(\mathrm{B}_{2}, \mathrm{~B}_{2}^{*}, T-t\right) \\
\mathrm{Q}_{2}(t, T)=\mathrm{L}_{2}^{*} \mathrm{P}_{2}(t, T)-\mathrm{P}\left(\mathrm{A}_{t}-\mathrm{Q}_{1}, \mathrm{~L}_{2}^{*}, T-t\right)+f_{y} \mathrm{P}_{\mathrm{A}}\left(\mathrm{B}_{2}, \mathrm{~B}_{2}^{*}, T-t\right)
\end{gathered}
$$

Where $f_{y}$ denotes the probability that the surrender options will be exercised. $\mathrm{Q}_{2}(t, T)$ denotes the value of the insurance life policies with the surrender option and $\mathrm{P}_{\mathrm{A}}(\ldots)$ denotes the value of an American Put option written on the underlying $\mathrm{B}_{2}(t, T)$, maturing at time $T$ and with exercise price $\mathrm{B}_{2} *$ that represents the refund value of the insurance life policies.

In Giandomenico(2006), we have:

$$
\begin{gathered}
\mathrm{P}_{\mathrm{A}}\left(\mathrm{B}_{1}, \mathrm{~B}_{1}^{*}, \tau-t\right)=\mathrm{B}_{1}^{*} \mathrm{~N}\left[\mathrm{~b}_{1}\right]-\mathrm{B}_{1}(t, \tau) \mathrm{N}\left[\mathrm{b}_{2}\right] \\
\mathrm{P}_{\mathrm{A}}\left(\mathrm{B}_{2}, \mathrm{~B}_{2}^{*}, T-t\right)=\mathrm{B}_{2}^{*} \mathrm{~N}\left[\mathrm{~b}_{3}\right]-\mathrm{B}_{2}(t, T) \mathrm{N}\left[\mathrm{b}_{4}\right]
\end{gathered}
$$

Where:

$$
\begin{aligned}
& \mathrm{b}_{1}=\frac{\ln \left(\mathrm{B}_{1} * / \mathrm{B}_{1}\right)+1 / 2 \sigma_{\mathrm{B}}^{2}(t, \tau)}{\sigma_{\mathrm{B}(t, \tau)} \sqrt{ }(\tau-t)} \\
& \mathrm{b}_{2}=\frac{\ln \left(\mathrm{B}_{1} * / \mathrm{B}_{1}\right)-1 / 2{\sigma_{\mathrm{B}}{ }^{2}(t, \tau)}(\tau-t)}{\sigma_{\mathrm{B}(t, \tau)} \sqrt{ }(\tau-t)} \\
& \mathrm{b}_{3}=\frac{\ln \left(\mathrm{B}_{2} * / \mathrm{B}_{2}\right)+1 / 2 \sigma_{\mathrm{B}}{ }^{2}(t, T)}{\sigma_{\mathrm{B}(t, T)} \sqrt{ }(T-t)}
\end{aligned}
$$




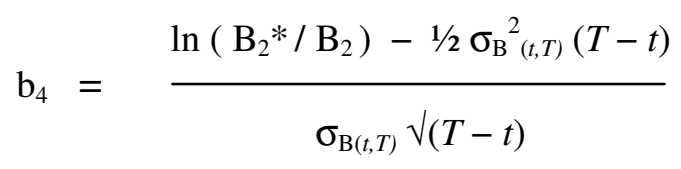

While:

$$
\begin{gathered}
\sigma_{\mathrm{B}(t, \tau)}^{2}=[1 /(\tau-t)] \int_{t}^{\tau} \sigma_{1}(t)^{2}+\sigma_{\mathrm{p}}(t, \tau)^{2}-2 \rho\left(\mathrm{B}_{1}, \mathrm{P}_{1}\right) \sigma_{1}(t) \sigma_{\mathrm{p}}(t, \tau) d t \\
\sigma_{\mathrm{B}(t, T)}^{2}=[1 /(T-t)] \int_{t}^{T} \sigma_{2}(t)^{2}+\sigma_{\mathrm{p}}(t, T)^{2}-2 \rho\left(\mathrm{B}_{2}, \mathrm{P}_{2}\right) \sigma_{2}(t) \sigma_{\mathrm{p}}(t, T) d t
\end{gathered}
$$

$\rho\left(\mathrm{B}_{1}, \mathrm{P}_{1}\right)$ represents the correlation between the liabilities $\mathrm{B}_{1}(t, \tau)$ and the riskless security $\mathrm{P}_{1}(t, \tau)$ $\rho\left(\mathrm{B}_{2}, \mathrm{P}_{2}\right)$ represents the correlation between the liabilities $\mathrm{B}_{2}(t, T)$ and the riskless security $\mathrm{P}_{2}(t, T)$ $\sigma_{1}(t)$ denotes the instantaneous volatility of the liabilities $\mathrm{B}_{1}(t, \tau)$ $\sigma_{2}(t)$ denotes the instantaneous volatility of the liabilities $\mathrm{B}_{2}(t, T)$

Thus, we have the following elasticity measure of the insurance liabilities:

$\eta_{\mathrm{L}}=-\frac{\left[\partial \mathrm{B}_{1}(t, \tau) / \partial r_{t}\right]\left(1-f_{x} \mathrm{~N}\left[\mathrm{~b}_{2}\right]\right) f_{x} \mathrm{~N}\left[\mathrm{~b}_{2}\right] \mathrm{N}\left[-\mathrm{h}_{1}\right]+\left[\partial \mathrm{B}_{2}(t, T) / \partial r_{t}\right]\left(1-f_{y} \mathrm{~N}\left[\mathrm{~b}_{4}\right]\right)}{\mathrm{L}_{t}}$

Where:

$$
\begin{gathered}
\mathrm{L}_{t}=\mathrm{Q}_{1}(t, \tau)+\mathrm{Q}_{2}(t, T) \\
\mathrm{h}_{1}=\frac{\ln \left\{\left(\mathrm{A}_{t}-\mathrm{Q}_{1}\right) /\left[\mathrm{L}_{2} * \mathrm{P}_{2}(t, T)\right]\right\}+1 / 2 \sigma_{(t, T)}^{2}(T-t)}{\sigma_{(t, T)} \sqrt{ }(T-t)}
\end{gathered}
$$

We can note that the surrender options reduce the effective duration of the insurance liabilities, this means: 
Thus, we have the following prospect for the insurance liabilities duration:

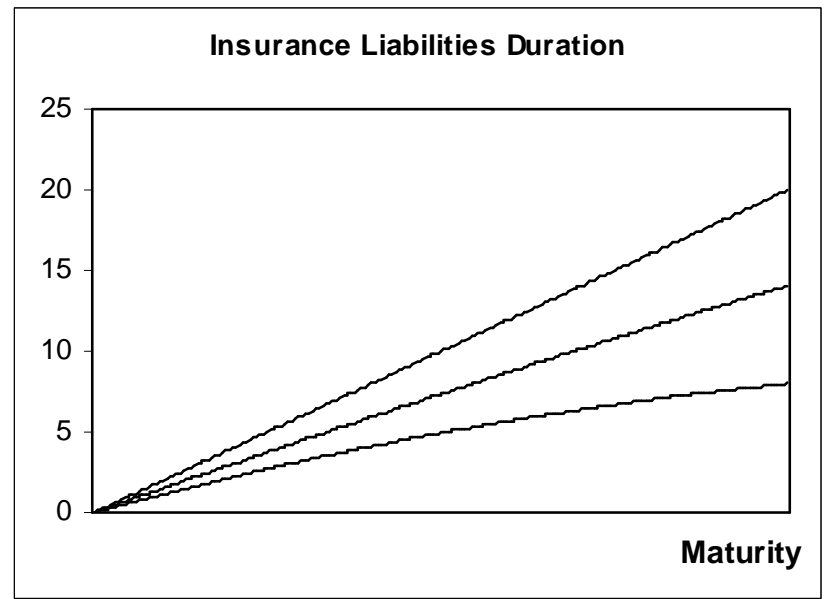

We can note that the surrender options reduce even more the duration of the insurance liabilities. In fact, to a maturity of twenty years corresponds a duration of eight years. If we assume that the weight of the bonds on the assets is less than the weight of the debt on the assets the Put options reduce even more the insurance liabilities duration Furthermore, in the case of mortality issue the cash-flows can occur sooner than expected, this brings us to think that it reduces the effective liabilities duration. In fact, it is like to sell an American Put option to the policyholders. We can note that if the interest rates increase such that the American Put options go deeper in-the-money, there is an incentive for the policyholders to exercise the surrender options. At the same time, if the value of assets decreases the American Put options go deeper in-the-money so to incentive the policyholders to exercise the surrender options. Insurers always insist upon the long maturity of their liabilities, but the message covered here is something different. As result, the behaviour of equity value resembles to a short position on the spot rate. Thus, we have the following prospect:

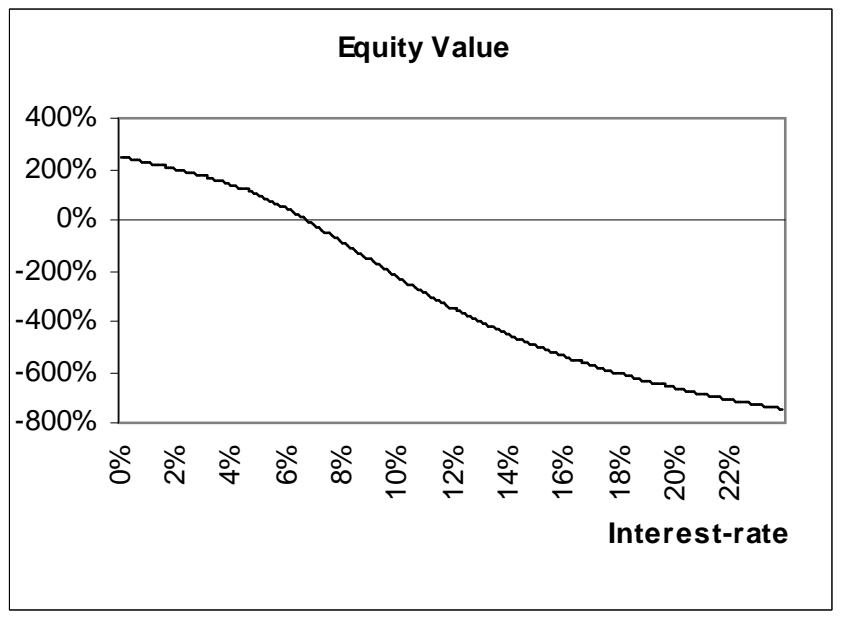

We can note that the Insurance Companies can be insolvent either if they invest prevalently in default free bonds. Thus, they have to hedge from the interest rate risk exposure to avoid the default risk. At this point, we can note that if interest rates increase there is an incentive for the policyholders to exercise the surrender options because the American Put options go deeper inthe-money and they are attracted from alternative investments that offer greater rate of return. As result, if policyholders exercise the surrender options we get a loss on the equity value given by the interest rates and the surrender options. This increases the risk of default so to decrease more 
the value of liabilities such that to increase the incentive to exercise the surrender options and the loss on the equity value. All this explains the problems of the insurance industry in the eighties when interest rates increased for the inflation. To avoid this result and the past mistakes we have to immunize the equity value by reducing the duration of assets and by putting a penalty on the insurance life policies in the case policyholders exercise the surrender options. If we reduce the weight of the bonds on the firm asset the behaviour of equity value resembles to a short position on a Collar written on the spot rate. Thus, we have the following prospect:

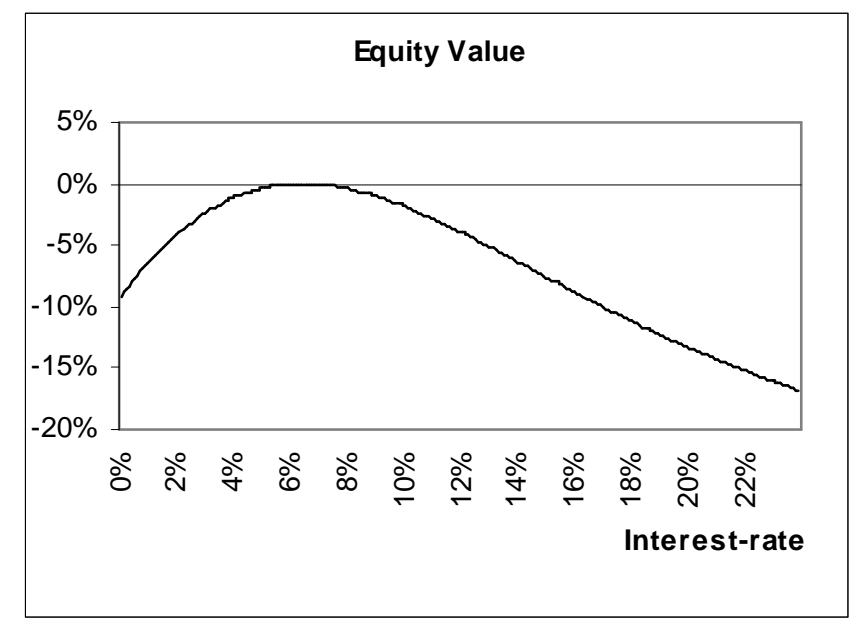

This result is due to the impact of the surrender options that increase the convexity of liabilities. Instead, if we reduce the maturity of assets we accept a parallel shift of the yield curve with respect to a movement of the spot rate. In this case, as we can see by the following figure, the behaviour of equity value resembles to a short position on a Straddle written on the spot rate.

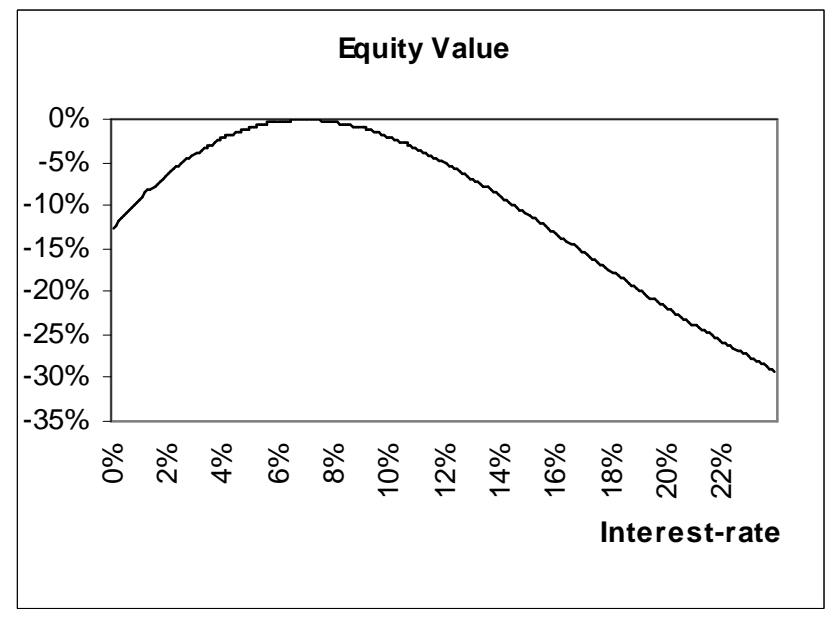

We can note that in this case the loss on the equity value with respect to a movement of the spot rate is greater; this is due to the greater spread between the convexity of assets and liabilities. Note that we can immunize the equity value in a perfect way by taking a long position on a Straddle written on the spot rate. Instead, if we assume that the interest rates are independent we can hedge from the risk of surrender options by taking a long position on a call option written on the interest rate for each maturity such that the value of assets doesn't decrease if interest rates increase. In the eighties the increasing competition for the savings brought Insurance Companies to offer greater rate of return on the insurance life policies. As result, they reached for riskier 
assets offering higher yields and operated with less capital per dollar of assets. When the Insurance Companies got loss on the value of assets the value of the insurance life policies decreased so to incentive the exercise of surrender options, this brought more loss on the equity value. Moreover, the increasing of default risk can bring policyholders to walk away by exercising the surrender options so to increase the loss on the equity value. Thus, the solution is to put a penalty on the insurance life policies in the case policyholders exercise the surrender options. We definitely conclude by noting that when we use the model to determine the fair value of the insurance life policies we have to consider the present value of the future cash-flows expected from the contracts as value of assets because they are credits of the Insurance Company. Whereas, as final value of the insurance life policies what expected to the end of the contracts. Moreover, we can get the fair fixed guaranteed interest rate of a new emission of insurance life policies maturing in $s>T$ by solving the following equation for the final value of the insurance life policies $\mathrm{L}_{3}^{*}$ :

$$
\mathrm{B}_{3}(t, s)=\mathrm{L}_{3} * \mathrm{P}(t, s)-\mathrm{P}\left(\mathrm{E}_{t}+\mathrm{B}_{3}(t, s), \mathrm{L}_{3} *, s-t\right)
$$

$\mathrm{B}_{3}(t, \mathrm{~s})$ is equal to the present value of the future cash-flow expected in the insurance life policies contracts with the same time of maturity. The value of equity must be computed on the base of the future value of assets. In fact, the value of assets increases for the amount of the value of new debt. Therefore, the value of old liabilities increases so to reduce the value of equity. Hence, the model suggests that a new emission of debt decreases the value of equity from a point of view of fair value, this doesn't mean that we get a loss on the equity value because the value of old liabilities, anyway, will converge to the same final value. Thus, from a point of view of the company the right value of the new debt must be computed with the old value of equity. The problem of this procedure is that we have to do a hypothesis on the number of insurance life policies with the same time of maturity that will be underwritten. If we assume that in every instant the Insurance Company underwrites one insurance life policy we can get that the fair fixed guaranteed interest rate is an increasing function of the insurance life policy value, or from another point of view, that it is an increasing function of the number of insurance life policies that will be underwritten, this is due to the increasing of the default risk. Moreover, we can note that for $s<T$ the fair fixed guaranteed interest rate is less because the risk of default is less. We have to note that this approach is based on the hypothesis that the Insurance Companies discount in the financial market their credits, operations of this kind take place in London, where the Reinsurance Companies take either the risk that the insurance life policies underwritten will decrease. Instead, if the Insurance Companies don't discount their credits, they are exposed to the risk that they can't invest the future cash-flows at the same risk free interest rate. Hence, we can assume that Insurance Companies live in a world where the risk free interest rate for each maturity is determined on the base of the forward rate.

\section{Conclusion}

By using a contingent claim approach we have developed a model for the fair valuation of insurance liabilities accounting for the default risk, the surrender possibility and the interest rate risk. The effective measure of insurance liabilities duration has been presented in opposite to the actuarial approach based on long term view. The immunization of equity value has been achieved by using a perfect hedge ratio. The insurance liabilities duration has been showed very short; hence, Insurance Companies need a rethinking of their duration in order to avoid that a mismatch between the duration of assets and liabilities jeopardizes the equity value.

I thank Prof. Franco Nardini, University of Bologna, Prof. Eric Briys, HEC School of Management, My Family and some other anonymous for the contributions. 


\section{References}

Babbel, D.F. :

Economic Valuation Models for Insurers

Wharton Financial Institutions Center, Working Paper 97-44, 1997

Bielecki, T. R., and Rutkowski, M.: Credit Risk: Modeling, Valuation and Hedging Springer Finance, 2002

Bjòrk, T. :

Arbitrage Theory in Continuous Time

Oxford University Press, 1998

Black, F., Cox, J. C. : Valuing Corporate Secutities: Some Effects of the Bond Identure Provisions Journal of Finance, Vol. 31, pag. 351-367, 1976

Black, F., Scholes, M. : $\quad$ The Pricing of Options and Corporate Liabilities Journal of Political Economy, pag.637-659, 1973

Brigo, D.,Mercurio, F. :

Interest Rate Model

Springer Finance, 2006

Briys, E., De Varenne, F. : $\quad$ Valuing Risky Fixed Rate Debt : An Extension Journal of Financial and Quantitative Analysis, Vol. 31 ; pag. 239-248, 1997

Briys, E., De Varenne, F. :

Insurance

John Wiley \& Sons, LTD (New York), 2001

Briys, E., De Varenne, F. : $\quad$ Life Insurance in a Contingent Claim Framework:

Pricing and Regulatory Implications

The Geneva Papers on Risk and Insurance Theory

Vol. 19, n 1 , pag. 53-72, 1994

Briys, E., De Varenne, F. : On the Risk of Insurance Liabilities: Debunking Some Common Pitfalls Journal of Risk and Insurance, Vol. 64, n²4, pag. 673-694, 1997

Duffie, D. , Singleton, K. J. : An Econometric Model of the Term Structure of Interest rate Swap Yields Journal of Finance 52, pag. 1287-1321, September 1997

Geske, R. :

The Valuation of Compound Options Journal of Financial Economics,Vol.7, pag. 63-81, 1979

Geske, R. :

The Valuation of Corporate Liabilities as Coumpond Options Journal of Financial and Quantitative Analysis, Vol. 12, pag 541-552; 1977

Geske, R., Johnson, H.E. :

The American Put Option Valued Analytically The Journal of Finance, Vol. 39, n 5, Dec. 1984

Giandomenico, R. : Pricing of the Insurance life policy in Absence of Default risk and Asset Liability Management

Social Science Research Network, 2006

Giandomenico, R. :

Valuing an American Put Option

Social Science Research Network, 2006 
Giraldi, C., Susino, G. :

Insurance Optional

Risk, April 2000

Heath, D., Jarrow, R., Morton. A. : Bond Pricing and the Term Structure of Interest Rates: a New Methodology for Contingent Claims Valuation Econometrica, Vol. 60(1), pag. 77-105, 1992

Jarrow, R. A. Turnbull, S. : Pricing Options on Derivative Securities Subject to Credit Risk Journal of Finance, Vol. 50, pag. 53-85, 1995

Lando, D. :

On Cox Processes and Credit Risky Securities Review of Derivatives Research, Vol. 2, pag. 99-120, 1998

Longstaff, F. A., Schwartz, E. S. : A Simple Apprach to Valuing Risky Fixed Floating Rate Debt Journal of Finance, Vol. 50, pag. 789-819, 1995

Louis Bachelier

Theory of Speculation (1900)

Cootner: The Random Character of Stock Market Prices

Cambridge, Mass, MIT. , 1964

Macaulay, F. R. : $\quad$ Some Theoretical Problems Suggested by the Movements of Interest Rates National Bureau of Economic Research, New York, 1938

Merton, R. :

The Theory of Rational Option Pricing

Bell Journal of Economics and Management Science, pag.141-183, 1973b

Merton, R. : $\quad$ On the Pricing of Corporate Debt: The Risk Structure of Interest Rate The Journal of Finance, Vol. 29, pag. 449-470, 1974

Merton, R. : $\quad$ On the Mathematics and Economics Assumptions of Continuous-Time Models Massachusetts Institute of Technology, 1982

Redington, F. M. :

Vasicek, O. :

Zhang, P. :
Review of the Principles of Life Office Valuations Journal of the Institute of Actuaries, 1952 Vol. 78 , part. $3, n^{\circ} 350$, pag. $286-340$

An Equilibrium Characterization of the Term Structure Journal of Financial Economics, pag.177-188, 1977

World Scientific, 1998 


\section{Footnotes}

$(1 *)$

Otherwise, if $T<\tau$, we have:

$$
\sigma_{\mathrm{C}}=\left(\partial \mathrm{C} / \partial \mathrm{A}_{t}\right)\left(\mathrm{A}_{t} / \mathrm{C}\right) \sigma_{\mathrm{A}}
$$

Where $\sigma_{\mathrm{C}}$ denotes the instantaneous volatility of the option $\mathrm{C}\left(\mathrm{A}_{t}, \mathrm{~L}_{1} *, \tau-t\right)$. This can be demonstrated explicitly by taking the instantaneous covariance of the instantaneous return on the option with itself and noting that changes in the option price are perfectly correlated with changes in the value of the firm asset. See Geske(1979)

In the case of participation to the profit, we have:

$$
\begin{gathered}
\mathrm{E}_{t}=\mathrm{C}\left(\mathrm{A}_{t}-\mathrm{B}_{1}, \mathrm{~L}_{2} *, T-t\right)-\beta_{2} \alpha_{2} \mathrm{C}\left(\mathrm{A}_{t}-\mathrm{B}_{1}, \mathrm{~L}_{2} * / \alpha_{2}, T-t\right) \\
\mathrm{B}_{2}(t, T)=\mathrm{L}_{2} * \mathrm{P}_{2}(t, T)-\mathrm{P}\left(\mathrm{A}_{t}-\mathrm{B}_{1}, \mathrm{~L}_{2} *, T-t\right)+\beta_{2} \alpha_{2} \mathrm{C}\left(\mathrm{A}_{t}-\mathrm{B}_{1}, \mathrm{~L}_{2} * / \alpha_{2}, T-t\right) \\
\mathrm{B}_{1}(t, \tau)=\mathrm{L}_{1} * \mathrm{P}_{1}(t, \tau)-\mathrm{P}\left(\mathrm{A}_{t}, \mathrm{~L}_{1} *, \tau-t\right)+\beta_{1} \alpha_{1} \mathrm{C}\left(\mathrm{A}_{t}, \mathrm{~L}_{1} * / \alpha_{1}, \tau-t\right)
\end{gathered}
$$

Where:

$\beta_{1}$ denotes the participation coefficient of $\mathrm{B}_{1}(t, \tau)$

$\beta_{2}$ denotes the participation coefficient of $\mathrm{B}_{2}(t, T)$

$$
\begin{gathered}
\alpha_{1}=\mathrm{B}_{1}(t, \tau) / \mathrm{A}_{t} \\
\alpha_{2}=\mathrm{B}_{2}(t, T) /\left(\mathrm{A}_{t}-\mathrm{B}_{1}\right) \\
\mathrm{C}\left(\mathrm{A}_{t}, \mathrm{~L}_{1} * / \alpha_{1}, \tau-t\right)=\mathrm{A}_{t} \mathrm{~N}\left[\mathrm{~d}_{3}\right]-\mathrm{P}_{1}(t, \tau)\left(\mathrm{L}_{1} * / \alpha_{1}\right) \mathrm{N}\left[\mathrm{d}_{4}\right] \\
\mathrm{C}\left(\mathrm{A}_{t}-\mathrm{B}_{1}, \mathrm{~L}_{2} * / \alpha_{2}, T-t\right)=\left(\mathrm{A}_{t}-\mathrm{B}_{1}\right) \mathrm{N}\left[\mathrm{h}_{3}\right]-\mathrm{P}_{2}(t, T)\left(\mathrm{L}_{2} * / \alpha_{2}\right) \mathrm{N}\left[\mathrm{h}_{4}\right]
\end{gathered}
$$

Where:

$\mathrm{N}[\ldots]$ denotes the cumulative normal distribution

$$
\begin{aligned}
& \mathrm{d}_{3}=\frac{\ln \left\{\mathrm{A}_{t} /\left[\left(\mathrm{L}_{1} * / \alpha_{1}\right) \mathrm{P}_{1}(t, \tau)\right]\right\}+1 / 2 \sigma_{(t, \tau)}^{2}(\tau-t)}{\sigma_{(t, \tau)} \sqrt{ }(\tau-t)} \\
& \mathrm{d}_{4}=\frac{\frac{\ln \left\{\mathrm{A}_{t} /\left[\left(\mathrm{L}_{1} * / \alpha_{1}\right) \mathrm{P}_{1}(t, \tau)\right]\right\}-1 / 2 \sigma_{(t, \tau)}^{2}(\tau-t)}{\sigma_{(t, \tau)} \sqrt{ }(\tau-t)}}{\mathrm{h}_{3}=\frac{\ln \left\{\left(\mathrm{A}_{t}-\mathrm{B}_{1}\right) /\left[\left(\mathrm{L}_{2} * / \alpha_{2}\right) \mathrm{P}_{2}(t, T)\right]\right\}+1 / 2 \sigma_{(t, T)}^{2}(T-t)}{\sigma_{(t, T)} \sqrt{ }(T-t)}} \\
& \mathrm{h}_{4}=\frac{\ln \left\{\left(\mathrm{A}_{t}-\mathrm{B}_{1}\right) /\left[\left(\mathrm{L}_{2} * / \alpha_{2}\right) \mathrm{P}_{2}(t, T)\right]\right\}-1 / 2 \sigma_{(t, T)}^{2}(T-t)}{\sigma_{(t, T)} \sqrt{ }(T-t)}
\end{aligned}
$$


Note that the third term in the insurance life policies value is a Call option on the performance of the Insurance Company assets (dividends, net capital gain, coupons, rents...). It represents the potential bonus weighted by the participation coefficient and the weight of the insurance life policies on the firm asset.

Another characteristic in the Call option is the exercise price such that policyholders begin to share the profit when the rate of return of the firm asset is greater than the fixed guaranteed interest rate, or alternatively, when the fixed guaranteed interest rate is fulfilled such that $\alpha_{1} A_{t}>L_{1} *$ and $\alpha_{2}\left(A_{t}-B_{1}\right)>L_{2} *$.

This means that shareholders not subsidize policyholders and that policyholders not subsidize shareholders. In fact, policyholders participate just to the profit generated from their initial investment.

Note that we can get the fair guaranteed interest rates and participation coefficients by solving the following equations:

$$
\begin{gathered}
\mathrm{C}\left(\mathrm{A}_{t}, \mathrm{~L}_{1} *, \tau-t\right)-\beta_{1} \alpha_{1} \mathrm{C}\left(\mathrm{A}_{\mathrm{o}}, \mathrm{L}_{1} * / \alpha_{2}, \tau-t\right)=\left(1-\alpha_{1}\right) \mathrm{A}_{t} \\
\mathrm{C}\left(\mathrm{A}_{t}-\mathrm{B}_{1}, \mathrm{~L}_{2} *, T-t\right)-\beta_{2} \alpha_{2} \mathrm{C}\left(\mathrm{A}_{t}-\mathrm{B}_{1}, \mathrm{~L}_{2} * / \alpha_{2}, T-t\right)=\left(1-\alpha_{2}\right)\left(\mathrm{A}_{t}-\mathrm{B}_{1}\right)
\end{gathered}
$$

But we can get an explicit formula just for the participation coefficients:

$$
\begin{aligned}
& \beta_{1}=\frac{\mathrm{C}\left(\mathrm{A}_{t}, \mathrm{~L}_{1} *, \tau-t\right)-\left(1-\alpha_{1}\right) \mathrm{A}_{t}}{\alpha_{1} \mathrm{C}\left(\mathrm{A}_{t}, \mathrm{~L}_{1} * / \alpha_{2}, \tau-t\right)} \\
& \beta_{2}=\frac{\mathrm{C}\left(\mathrm{A}_{t}-\mathrm{B}_{1}, \mathrm{~L}_{2} *, T-t\right)-\left(1-\alpha_{2}\right)\left(\mathrm{A}_{t}-\mathrm{B}_{1}\right)}{\alpha_{2} \mathrm{C}\left(\mathrm{A}_{t}-\mathrm{B}_{1}, \mathrm{~L}_{2} * / \alpha_{2}, T-t\right)}
\end{aligned}
$$

See Briys, De Varenne(2001)

If in the case of insolvency the total value of assets is shared between all policyholders we have the following:

$$
\begin{gathered}
\mathrm{L}_{1}(t, \tau)=\mathrm{L}_{1} * \mathrm{P}_{1}(t, \tau)-\mathrm{P}\left(\mathrm{A}_{t}, \mathrm{~L}_{1} *, \tau-t\right)-\left(\mathrm{L}_{2} * / \mathrm{L}_{1} *+\mathrm{L}_{2} *\right) \mathrm{P}\left(\mathrm{A}_{t}, \mathrm{~L}_{1} *, \tau-t\right) \\
\mathrm{L}_{2}(t, T)=\mathrm{L}_{2} * \mathrm{P}_{2}(t, T)-\mathrm{P}\left(\mathrm{A}_{t}-\mathrm{B}_{1}, \mathrm{~L}_{2} *, T-t\right)+\left(\mathrm{L}_{2} * / \mathrm{L}_{1} *+\mathrm{L}_{2} *\right) \mathrm{P}\left(\mathrm{A}_{t}, \mathrm{~L}_{1} *, \tau-t\right) \\
\mathrm{E}_{t}=\mathrm{C}\left(\mathrm{A}_{t}-\mathrm{B}_{1}, \mathrm{~L}_{2} * T-t\right)
\end{gathered}
$$

Where we denote with $\mathrm{L}_{1}(t, \tau)$ the fair value of the insurance life policies with time of maturity $\tau$, and with $\mathrm{L}_{2}(t, T)$ the fair value of the insurance life policies with time of maturity $T$. We can note that if the debt is subordinated, or not, doesn't change the value of equity.

In the case of participation to the profit we have the following elasticity measure of insurance liabilities:

$$
\begin{gathered}
\eta_{\mathrm{L}}=\left[\mathrm{L}_{1} * \mathrm{P}_{1}(t, \tau) / \mathrm{L}_{t}\right] \eta_{\mathrm{p}(t, \tau)}+\left[\mathrm{L}_{2} * \mathrm{P}_{2}(t, T) / \mathrm{L}_{t}\right] \eta_{\mathrm{p}(t, T)} \\
+\left(\mathrm{A}_{t} \eta_{\mathrm{A}} / \mathrm{L}_{t}\right)\left\{\mathrm{N}\left[-\mathrm{d}_{1}\right]+\beta_{1} \alpha_{1} \mathrm{~N}\left[\mathrm{~d}_{3}\right]+\left\{\left(\mathrm{N}\left[\mathrm{d}_{1}\right]-\beta_{1} \alpha_{1} \mathrm{~N}\left[\mathrm{~d}_{3}\right]\right)\left(\mathrm{N}\left[-\mathrm{h}_{1}\right]-\beta_{2} \alpha_{2} \mathrm{~N}\left[\mathrm{~h}_{3}\right]\right)\right\}\right\} \\
-\left[\mathrm{L}_{1} * \mathrm{P}_{1}(t, \tau) \eta_{\mathrm{p}(t, \tau)} / \mathrm{L}_{t}\right]\left\{\mathrm{N}\left[-\mathrm{d}_{2}\right]+\beta_{1} \mathrm{~N}\left[\mathrm{~d}_{4}\right]+\left\{\left(\mathrm{N}\left[\mathrm{d}_{2}\right]-\beta_{1} \mathrm{~N}\left[\mathrm{~d}_{4}\right]\right)\left(\mathrm{N}\left[-\mathrm{h}_{1}\right]-\beta_{2} \alpha_{2} \mathrm{~N}\left[\mathrm{~h}_{3}\right]\right)\right\}\right\} \\
-\left[\mathrm{L}_{2} * \mathrm{P}_{2}(t, T) \eta_{\mathrm{p}(t, T)} / \mathrm{L}_{t}\right]\left\{\mathrm{N}\left[-\mathrm{h}_{2}\right]+\beta_{2} \mathrm{~N}\left[\mathrm{~h}_{4}\right]\right\}
\end{gathered}
$$

We can note that the participation to the profit increases the impact of the Put options on the insurance liabilities duration. Thus, it decreases, or increases, more the effective liabilities duration. 